\title{
$\mathrm{PP} /$ talc 컴파운드의 talc 분산성 및 유변학적 특성 연구
}

\author{
유영철 ${ }^{*}$, 김연철 ${ }^{1}$ \\ ${ }^{1}$ 공주대학교 신소재공학부 고분자공학전공

\section{Study on the talc dispersion and rheological properties of PP/talc compound}

\author{
Young Chul You ${ }^{1 *}$ and Youn Cheol Kim ${ }^{1}$ \\ ${ }^{1}$ Major in Polymer Science \& Engineering, Kongju National University
}

\begin{abstract}
요 약 폴리프로필렌(polypropylene, PP)/talc 컴파운드를 talc의 조성을 $20 \mathrm{wt} \%$ 로 하여 마스터뱃취(master-batch, MB) 와 사출기를 이용한 직접 제조법으로 각각 제조하였다. $\mathrm{MB}$ 는 talc 함량을 $50 \mathrm{wt} \%$ 로 하여 소형 혼합기(mini compounder) 로 $200^{\circ} \mathrm{C}$ 에서 제조하였다. SEM-EDS를 이용하여 PP/talc 컴파운드의 talc 분산정도를 평가하였다. MB를 이용하여 제 조한 컴파운드의 talc 분산성이 우수하게 나타났다. $\mathrm{PP} / \mathrm{talc}$ 컴파운드의 유변학적 특성을 동적유변측정기를 이용하여 측정하였다. $\mathrm{MB}$ 를 이용한 $\mathrm{MB}-\mathrm{PP}$ 컴파운드가 직접 제조한 컴파운드보다 shear thinning과 탄성특성이 증가하였다. $\mathrm{G}^{\prime}-\mathrm{G}^{\prime \prime}$ plot의 기울기 변화로부터 talc 분산성 정도를 확인하였고, 탄성특성 증가를 확인하기 위해 Van Gurp-Palmen 분석을 이용하였다.
\end{abstract}

\begin{abstract}
Polypropylene (PP)/talc compounds with talc content of $20 \mathrm{wt} \%$ were fabricated by master-batch (MB) and direct compounding method using injection molding. The MB was prepared by mini compounder at $200^{\circ} \mathrm{C}$ and the content of talc was $50 \mathrm{wt} \%$. The talc dispersion of the PP/talc compound was investigated by SEM-EDS. The talc was well dispersed within PP matrix in case of the MB-PP compound using MB. The rheological properties of the PP/talc compounds were measured by dynamic Rheometer. The MB-PP compound indicates higher shear thinning and elastic property than direct compound. The disperion of talc was certified by G'-G" plot, and Van Gurp-Palmen analysis was applied in order to certify an increase in elasticity.
\end{abstract}

Key Words : Polypropylene, Talc, Mater- batch, Dispersion, Rheological Properties

\section{1. 서론}

폴리프로필렌(Polypropylene, PP)은 분자구조가 탄소 와 수소만으로 이뤄져 있기 때문에 리사이클링시 폴리머 의 성능 저하가 없다는 점과 소각시에도 유해 독성 가스 를 발행시키지 않는다는점 등 다양한 친환경적 요소를 갖추고 있어 환경문제를 중요시하는 선진국 시장에서는 이미 친환경 소재로서 그 용도를 확대하고 있다. 또한, $\mathrm{PP}$ 소재는 모든 고분자 소재 가운데 가장 가볍기 때문에 경량 소재로 주목을 받고 있다. 이와 같은 환경적 특성과
여러 가지 기술적 특성으로 인해 $\mathrm{PP}$ 는 범용 및 산업용 소 재로서의 시장 규모를 확대해 나가고 있다. 그러나 $\mathrm{PP}$ 의 경우 강도 및 열팽창계수 등이 열세하여 자동차용 소재 와 같은 산업용 소재로 활용되기 위해서는 이들 물성의 개선이 요구되고, 물성 개선을 위해 무기필러(inorganic filler)가 혼입된 컴파운드(compound)의 첨가제 분산성과 이에 따른 유변학적 특성 및 수축율 등의 특성 평가가 필 요하고, 이에 대한 많은 연구들이 진행되었다[1-7].

이와 같은 무기필러가 함유된 PP 컴파운드는 현재 컴 파운드 제조업체에서 구매하여 사용하는데, 이는 원가 상

본 논문은 2010년도 정부(교육과학기술부)의 재원으로 한국연구재단의 지원(No. 2010-0022015)과 지식경제부 지정 공주대 학교 자동차의장 및 편의부품 지역혁신센터의 지원에 의한 것입니다.

"교신저자 : 김연철(younkim@kongju.ac.kr)

접수일 11년 08월 03일 수정일 11년 08월 26일

게재확정일 11 년 09 월 08 일 
승의 원인으로 작용하고 있다. 복합 $\mathrm{PP}$ 의 비용 절감을 위 해 컴파운드 업체의 복합 $\mathrm{PP}$ 를 구매하지 않고, 생산현장 에 설치된 사출기에서 직접 컴파운딩(In Line Compounding, 이하 ILC)하는 기술을 적용하기 위한 방편으로 ILC에 따 른 무기필러(예 talc 등) 의 분산성을 확보하고, 선팽창계 수 및 유변학적 특성 등을 평가하여, 최종적으로 자동차 용 부품 소재로 적용이 가능한 ILC형 복합 $\mathrm{PP}$ 의 formulation을 최적화하려는 노력이 부품 업체를 중심으 로 진행되고 있다[8]. 여기서 ILC 방식은 PP, 엘라스토머 (elastomer), talc 및 기타 첨가제등을 각각 직접 정량공급 계량장치를 통해 사출기에 공급하여 부품을 제작하는 방 식을 말한다. ILC 제조기술 적용시 무기 첨가제의 직접 공급은 분산성의 불량을 가져와 최종적인 컴파운드의 물 성에 영향을 주기 때문에 $\mathrm{MB}$ 도입을 통한 분산성의 개 선 및 기계적, 유변학적 특성에 대한 고찰이 요구된다.

고분자 재료의 유변학적 특성은 고분자 재료의 성형가 공시 중요한 변수중 하나일 뿐만아니라 낮은 전단영역에 서의 용융점도로부터 탄성특성 및 heterogeneous 용융체 에 대한 정보를 유추할 수 있기 때문에 많은 연구들이 진 행되어 왔다[9-13]. 이들 연구 결과를 요약해 보면, 고분 자/무기필러 복합체에서 무기필러의 분산이나 계면접착 특성이 좋아지면 용융상태에서 무기필러에 의한 고체특 성이 고분자 용융체에 영향을 미쳐 용융점도에 있어서 shear thinning 효과가 두드러지게 나타나고, 낮은 전단영 역에서의 용융점도가 큰 폭으로 증가하는 결과들로 요약 할 수 있다.

따라서 본 연구에서는 $\mathrm{PP} / \mathrm{talc}$ 컴파운드를 사출기를 이 용한 직접방법과 talc $\mathrm{MB}$ 를 mini compounder를 이용하 여 제조한 후 컴파운드를 제조하는 방법으로 $\mathrm{PP} / \mathrm{talc}$ 컴 파운드를 각각 제조하여 talc의 분산성 및 유변학적 특성 을 평가하고, 제조방법에 따른 talc의 분산성과 유변학적 특성의 상관관계를 고찰하고자 하였다.

\section{2. 실험}

\section{1 실험재료}

실험에 사용된 PP는 대한유화의 용융지수(melt index, MI) $30 \mathrm{~g} / 10 \mathrm{~min}$ 의 블럭 PP를 사용하였고, Talc (Magnesium silicate hydrous, $3 \mathrm{MgO} \cdot 4 \mathrm{SiO}_{2} \cdot \mathrm{H}_{2} \mathrm{O}$ )는 용융온도 $800^{\circ} \mathrm{C}$, 분자량 $379.28 \mathrm{~g} / \mathrm{mol}$ 의 삼전화학 제품을 사용하였다. 상 업용 PP 컴파운드는 talc 함량 $20 \mathrm{wt} \%$, 용융지수 $21 \mathrm{~g} / 10 \mathrm{~min}$ 의 제품을 사용하였다.

\section{2 실험방법}

\subsubsection{PP/talc 컴파운드의 제조}

$\mathrm{PP}$ 컴파운드는 PP에 talc를 $20 \mathrm{wt} \%$ dry blend하여 일 축 사출기(대창기계공업(주) DC-90-PP)에 바로 투입하여 제조한 시료(direct compound) 와 자체 제작한 mini compounder를 이용하여 talc $50 \mathrm{wt} \%$ 마스터뱃취 (masterbatch, MB)를 제조한 후 일축 사출기를 이용하여 $20 \mathrm{wt} \%$ 컴파운드를 $200^{\circ} \mathrm{C}$ 에서 제조하였다. 그림 1 에 각각의 시 료에 대한 DSC thermogram을 나타내었다.

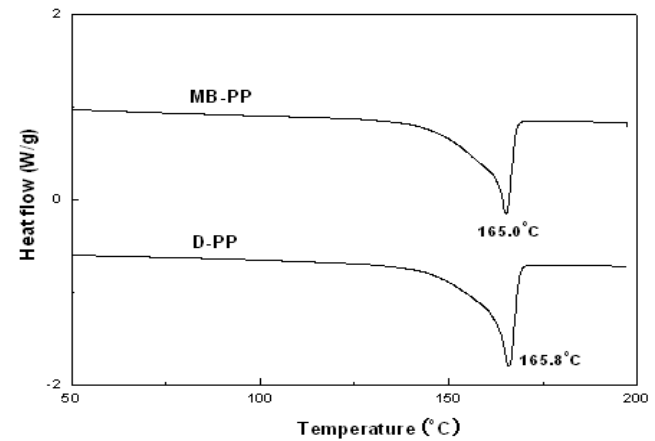

[그림 1] D-PP와 MB-PP의 DSC thermograms/

[Fig. 1] DSC thermograms of the compounded PP

\subsection{2 측정}

시차주사열용량(DSC)의 측정은 TA Instruments 10 을 이용하였으며, 승온속도는 $10{ }^{\circ} \mathrm{C} / \mathrm{min}$ 로 고정하였다. 모든 열분석은 질소분위기하에서 수행하였다. SEM-EDS 측정 은 Tescan의 SEM(MIRA LMH)을 이용하여 분석하였다. 유변학적 특성을 측정하기 위해서 동적 유변측정기를 사 용하였다. 동적 유변측정기는 Anton Parr사의 ARES를 사용하여, strain $10 \%$, 주파수 $0.05-500 \mathrm{~Hz}, \mathrm{Gap}$ size $1.0 \mathrm{~mm}$ 의 조건으로 $180^{\circ} \mathrm{C}$ 에서 측정하였다. 직경 $25 \mathrm{~mm}$ 의 parallel plate를 사용하여 실험을 수행하였다. 시편은 $1800^{\circ} \mathrm{C}$ 가열프레스를 이용하여 제작하였고, 시료를 10 $0^{\circ} \mathrm{C}$ 진공오븐에서 10 시간 이상 건조 후 사용하였다.

\section{3. 결과 및 고찰}

$\mathrm{D}-\mathrm{PP}$ 와 MB-PP의 talc 분산성을 비교하기 위해 일반사 진과 SEM 사진을 이용하였다. 그림 2는 두 시료의 일반 사진 결과를 보여주는 것이다. D-PP(그림 1 (a))의 경우 는 talc가 없는 부분과 뭉쳐 있는 부분(원형)이 존재하는 것을 알 수 있는 반면 MB-PP의 경우(그림 2 (b)) talc가 
고르게 분산되어 있는데, 이로부터 $\mathrm{MB}-\mathrm{PP}$ 의 분산성이 보다 우수함을 알 수 있다.

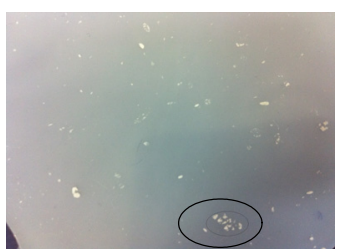

(a)

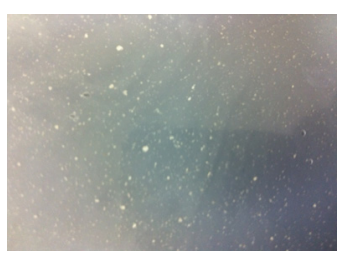

(b)
[그림 2] MB-PP(a) 와 D-PP(b)의 일반사진

[Fig. 2] Photos of MB-PP(a) and D-PP(b)

Talc의 분산정도를 보다 자세히 분석하기 위해 EDS가 부착된 전자주사현미경(Scanning Electron Microscope, $\mathrm{SEM}$ ) 실험을 수행하였다. 아래 그림 3은 상업화 PP 컴파 운드의 SEM-EDS 결과를 나타낸 것이다. SEM 사진에서 입자로 나타나는 부분의 원소분석 결과 $\mathrm{Si}, \mathrm{Mg}$ 등의 성 분이 검출되었고, 이로부터 무기물로 talc가 첨가된 컴파 운드임을 확인할 수 있다.
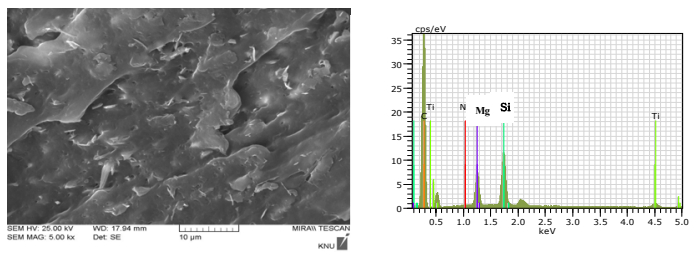

[그림 3] 상업화 PP 컴파운드의 SEM 결과

[Fig. 3] SEM results of commercial PP

다음 그림 4는 D-PP와 MB-PP의 talc 분산성을 비교하 기 위해 SEM-EDS 분석결과를 나타낸 것이다.
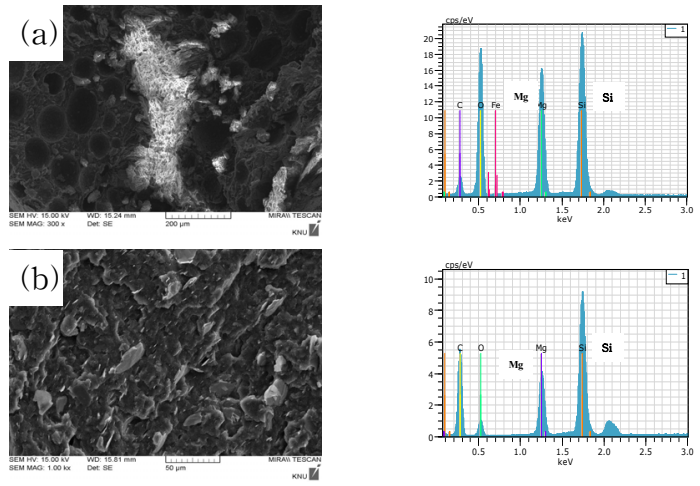

[그림 4] D-PP (a)과 MB-PP (b)의 SEM 결과

[Fig. 4] SEM results of D-PP(a) and MB-PP(b)
$\mathrm{D}-\mathrm{PP}$ 의 경우 위 그림에서 보여주는 것과 같이 일부가 뭉쳐있는 것을 알 수 있다. 반면 MB-PP의 경우는 전체적 으로 분산이 양호함을 알 수 있고, SEM 사진의 흰색 부 분을 원소 분석한 결과 $\mathrm{Si}, \mathrm{Mg}$ 등의 성분이 검출되어 talc 임을 확인할 수 있다.

일반적으로 고분자에 무기물이 첨가되면 유변학적 특 성에 큰 변화를 가져오게 된다. 우선 용융체내에 점탄성 특성 중에 탄성 특성이 증가하게 되고, 무기물 충진제는 낮은 전단장에서 비뉴톤 거동을 나타내는 원인을 제공하 여 zero shear viscosity를 큰 폭으로 증가시킴과 동시에 power law index의 감소를 가져오는 것으로 알려져 있다. Power law index의 감소는 가공영역에서의 용융점도 감 소를 가져오기 때문에 가공성 향상을 기대할 수 있다. 무 기물 충진제가 첨가된 경우와 첨가되지 않은 경우 고분 자 사슬에 전단장(shear stress field)이 걸리게 되면 서로 다른 유변학적 특성을 나타내게 된다. 무첨가 고분자의 경우 낮은 전단장에서 사슬의 신장이 발생하지 않기 때 문에 전단속도가 증가하여도 용융점도의 감소폭이 매우 좁다. 반면 무기물 충진제를 가지는 컴파운드의 경우는 낮은 전단장에서 고분자 용융체 내에서 고체와 같은 역 할을 하기 때문에 전단속도가 감소함에 따라 용융점도가 증가하게 되고, 이와 같은 현상을 shear thinning effect라 한다.

그림 5는 PP 컴파운드의 주파수(frequency)에 따른 복 합점도(complex viscosity, $n^{*}$ )를 나타낸 것이다.

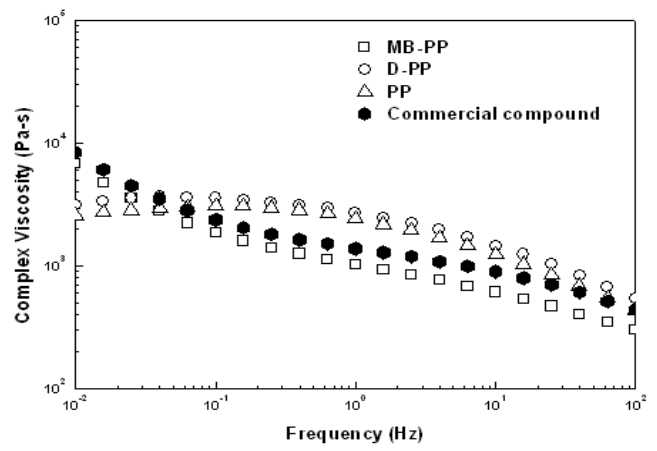

[그림 5] PP 컴파운드의 복합점도 곡선

[Fig. 5] Complex viscosity of PP compounds

순수 $\mathrm{PP}$ 의 복합점도는 고분자 용융체의 전형적인 형 태로 낮은 주파수에서는 뉴톤 거동을 보이다가 주파수가 증가하면서 고분자 사슬의 배향이 발생하여 점도가 감소 하는 shear thinning 현상을 보여주고 있다. 반면 talc를 포 함하는 상업화 PP 컴파운드의 경우는 낮은 주파수 영역 에서도 shear thinning 현상을 나타내고 있는데, 이는 앞 
에서 설명한 바와 같이 무기물 충진제에 의해 고체 특성 이 나타나기 때문으로 해석할 수 있다. MB50을 이용하 여 제조한 컴파운드 (MB-PP)의 경우 상업화 PP 컴파운 드와 유사한 복합점도 거동을 보이는 반면 D-PP의 경우 는 PP와 유사한 복합점도 pattern을 보이고 전체적으로 높은 복합점도 갚을 나타내고 있다. 복합점도의 증가는 사출가공시 흐름성이 약화되어 여러 가지 문제를 야기할 수 있는 가능성이 있다. 이와 같은 현상은 direct compound의 경우 talc가 PP 수지용융체내에 적절하게 분 산되어 있지 못해 무기 충진물의 역할(미세구조 변화)을 하지 못해 나타나는 현상으로 해석할 수 있다.

많은 연구자들이 고분자의 미세구조 변화에 $\mathrm{G}^{\prime}-\mathrm{G}^{\prime \prime}$ 곡 선을 이용하였다. 일반적으로 isotropic homogeneous 고 분자 용융체에서 terminal zone 기울기가 2를 나타내는 반면, mesophase와 블록공중합체 같은 heterogeneous 고 분자 용융체의 경우 2 보다 작은 값을 나타내는 것으로 설 명하고 있으며[14,15], 분지형 폴리프로필렌 연구에 있어 서 기울기의 감소를 보여주는데, 이는 완화거동의 변화로 설명하고 있다. 그림 6 은 PP 컴파운드들의 $200{ }^{\circ} \mathrm{C}$ 에서의 저장탄성률(storage modulus, $\mathrm{G}^{\prime}$ )과 손실탄성률(loss modulus, $\left.\mathrm{G}^{\prime \prime}\right)$ 곡선을 나타낸 것이다.

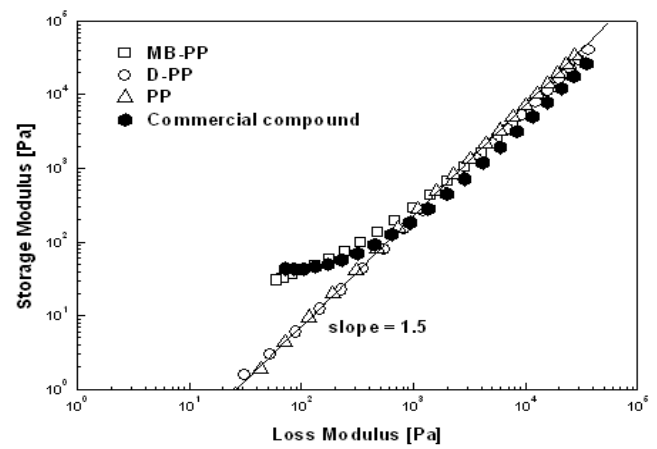

[그림 6] PP 컴파운드의 $\mathrm{G}^{\prime}-\mathrm{G}^{\prime \prime}$ 곡선

[Fig. 6] G'-G" plots of PP compounds

$\mathrm{PP}$ 의 경우 직선의 형태를 나타내고 있는데, 선형회귀 분석 결과 기울기가 1.5 를 나타내고 있다. 이는 사용한 $\mathrm{PP}$ 가 block PP로 용융상태에서 block들이 다른 상을 형 성하는 heterogeneous system을 나타내어 기울기가 2보다 작은 값을 나타내는 것으로 해석할 수 있다. D-PP의 경우 talc의 분산성이 충분하지 못해 PP와 유사한 기울기를 나 타내고 있는 반면 MB-PP의 경우 높은 탄성률 영역에서 는 PP와 유사한 거동을 나타내지만 낮은 탄성률(주파수) 영역에서는 탄성특성(고체특성)이 크게 증가하는 것을 볼 수 있다. 이와 같은 현상은 talc가 고분자 용융체에 첨
가되어 분자구조가 완화되는 시간을 증가시켜 나타나는 현상으로 유추할 수 있다.

$\mathrm{D}-\mathrm{PP}$ 대비 MB-PP의 유변학적 특성 변화를 보다 자세 히 관찰하기 위해 폴리올레핀에서 주로 사용하는 손실계 수 $\left(\tan \delta=\mathrm{G}^{\prime \prime} / \mathrm{G}^{\prime}\right)$ 와 Van Gurp-Palmen 분석[15]을 사용하였 다. 그림 7은 PP/talc 컴파운드의 주파수에 따른 손실계수 를 보여주는 것이다. 그림에서 볼 수 있듯이 PP 의 손실 계수가 주파수에 크게 의존하지 않는 것을 알 수 있고, 곡선의 형태 또한 큰 차이를 보이지 않음을 알 수 있다.

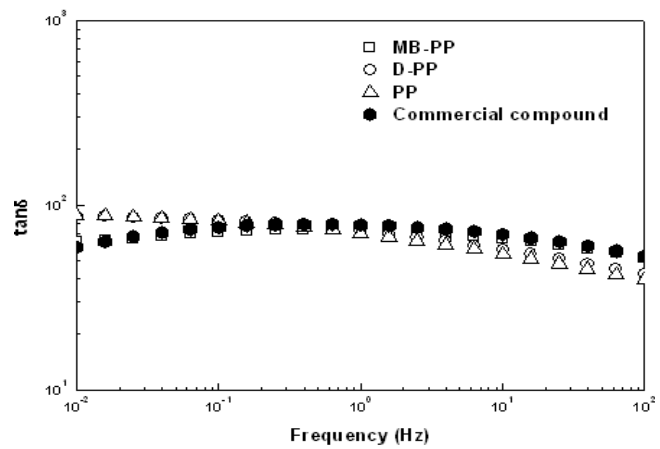

[그림 7] PP 컴파운드의 손실계수

[Fig. 7] $\tan \delta$ of PP compounds

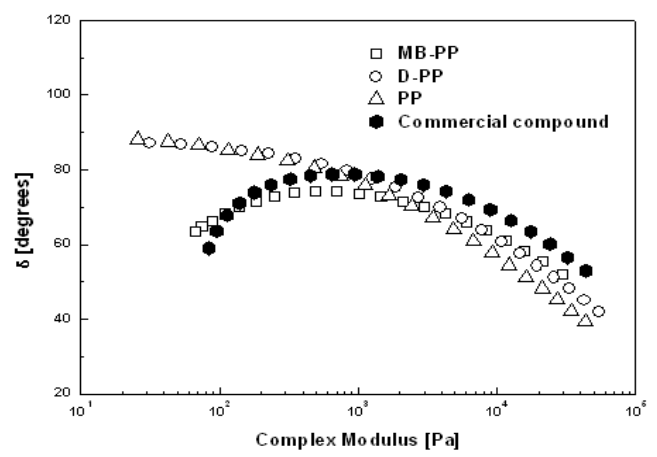

[그림 8] PP 컴파운드의 복합탄성률과 위상차 곡선

[Fig. 8] Plots for complex modulus vs. $\delta$ of of PP compounds

다음은 PP compound 들의 Van Gurp-Palmen 분석 결 과를 살펴보기 위해 복합탄성률 $\left(\sqrt{\left(G^{\prime 2}+G^{\prime \prime 2}\right)}\right)$ 과 위상차 ( $\delta$ 를 계산하여 그림 8 에 나타내었다. PP와 D-PP의 위상 차는 낮은 복합탄성률에서 $\pi / 2$ 에 가까워지고, 복합탄성률 에 따라 점차적으로 감소하는 곡선 형태를 보여주고 있 다. 반면 상업화 PP 컴파운드와 MB-PP의 위상차는 복합 탄성률이 낮아질수록 0 에 가까운 값으로 접근하는 것을 볼 수 있다. 완전 점성체의 위상차는 $\pi / 2$, 완전 탄성체의 
위상차는 0 으로 위상차가 작을수록 탄성체에 가까운 특 성을 가지게 된다. 즉, 상업화 $\mathrm{PP}$ 컴파운드 그리고 MB-PP과 같이 무기 충진제의 분산성이 우수할수록 초기 영역에서의 탄성특성이 두드러지게되고 이로 인해 위상 차가 감소하는 것으로 해석할 수 있다. 이들 결과로부터 Van Gurp-Palmen 분석은 무기 충진제-PP compound에서 충진제의 분산성을 확인하는데 효과적이라 할 수 있다.

\section{4. 결론}

폴리프로필렌에 $20 \mathrm{wt} \%$ 의 talc를 첨가하여 마스터뱃취 와 사출기를 이용한 직접 제조법으로 각각 $\mathrm{PP} / \mathrm{talc}$ 컴파 운드를 제조하고 분산성과 유변학적 특성을 평가하였다. $\mathrm{SEM}$ 분석결과 MB-PP의 talc 분산성이 우수하였다. $\mathrm{PP} / \mathrm{talc}$ 컴파운드의 복합점도 거동은 $\mathrm{D}-\mathrm{PP}$ 의 경우 $\mathrm{PP}$ 와 유사한 거동을 보이는 반면 MB-PP의 경우 낮은 주파수 영역에서도 shear thinning 현상을 나타내었고, 이는 PP내 의 talc 분산성과 연관된 것으로 해석할 수 있다. $\mathrm{PP}$ 나 D-PP와 비교할 때 MB-PP의 G'-G" plot의 기울기와 형태 가 변화하였는데 이는 talc 분산성이 향상되어 heterogeneous 용융체 특성을 나타나기 때문으로 판단된 다. 탄성 특성 변화를 확인하기 위해 Van Gurp-Palmen 분석을 적용하였다. 분석결과 MB-PP의 경우 낮은 주파 수 영역에서 위상차가 낮은 값을 보여주었고, 이는 탄성 특성의 증가를 나타내는 것이며, talc에 의한 고체특성이 고분자 용융체에 영향을 주어 나타나는 것으로 해석할 수 있다. D-PP의 경우 talc 분산성이 열세하여 $\mathrm{PP}$ 의 기계 적 물성의 개선효과를 나타나지 못하는 것으로 판단된다.

\section{References}

[1] M.i Fujiyama and T. Wakino, "Crystal orientation in injection molding of talc-filled polypropylene", J. of Appl. Polym. Sci., 42, 9-20, 1991.

[2] J. I. Velasco, J. A. De Saja, and A. B. Martínezl, "Fracture behavior of untreated and silane-treated talc-filled polypropylene composites", Fatigue \& Fracture of Eng. Mat. \& Structures, 20, 659-670, 1997.

[3] Y. Zhou and P. K. Mallick, "Effects of temperature and strain rate on the tensile behavior of unfilled and talc-filled polypropylene. Part I: Experiments", Polym. Eng. \& Sci., 42, 2449-2460, 2002.

[4] R. S. Hadal, A. Dasari2, and R. D. K. Misra, A
"Microstructural study of sequence of events leading to fracture of wollastonite-reinforced polypropylene composites during tensile loading", Microscope and Microanalysis, 10, 670-671, 2004.

[5] Y. Zhou and P. K. Mallick, "Effects of melt temperature and hold pressure on the tensile and fatigue properties of an injection molded talc-filled polypropylene", Polym. Eng. \& Sci., 45, 755-763, 2005.

[6] K. Shelesh-Nezhad and A. Taghizadeh, "Shrinkage behavior and mechanical performances of injection molded polypropylene/talc composites", Polym. Eng. \& Sci., 47,2124-2128, 2007.

[7] H. Azizi and J. Faghihi, "An investigation on the mechanical and dynamic rheological properties of single and hybrid filler/polypropylene composites based on talc and calcium carbonate", Polym. Compo., 30, 1743-1748, 2009.

[8] J. M. Cormont, "In line compounding and extrusion of PP with talc and chalk", Adv. in Polym. Techno., 5, 139-152, 1985.

[9] D. C. Goel, "Effect of polymeric additives on the rheological properties of talc-filled polypropylene", Polym. Eng. \& Sci., 20, 198-201, 1980.

[10] Y. C. Kim and J.-C. kim, "Study on the Silicate Dispersion and Rheological Properties of PP/Starch-MB/Silicate Composites", J. Ind. Eng. Chem., 13, 1029-1034, 2007.

[11] S. Duquesne1, F. Samyn1, S. Bourbigot, P. Amigouet, F. Jouffret, and K. Shen, "Influence of talc on the fire retardant properties of highly filled intumescent polypropylene composites", Polym. for Adv. Techno., 19, 620-627, 2008.

[12] Y. Jahani and M. Ehsani, "The rheological modification of talc-filled polypropylene by epoxy-polyester hybrid resin and its effect on morphology, crystallinity, and mechanical properties", Polym. Eng. \& Sci., 49, 619-629, 2009.

[13] Y. Jahani, "Comparison of the effect of mica and talc and chemical coupling on the rheology, morphology, and mechanical properties of polypropylene composites", Polym. for Adv. Techno.., 22, 942-950, 2011.

[14] C. D. Han, D. M. Baek, and J. G. Kim, "Effect of microdomain structure on the order-disorder transition temperature of polystyrene-block-polyisoprene-blockpolystyrene copolymers", Macromolecules, 23, 561-570, 1990.

[15] D. J. Lohse, S. T. Milner, L. J. Fetters, and Xenidou, "Well-Defined, Model Long Chain Branched Polyethylene. 
2. Melt Rheological Behavior", Macromolecules, 35, 3066-3075 2002.

\section{김 연 철(Youn Cheol Kim)}

[정회원]

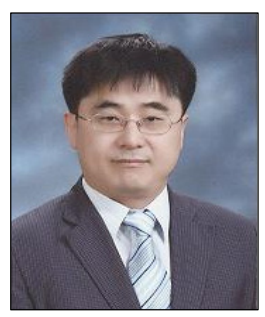

- 1994년 2월 : 한국과학기술원 화 학공학과 (공학박사)

- 1994년 2월 1996년 12월 : 삼 성종합화학연구소 선임연구원

- 1997년 7월 1998년 9월 : 일 리노이대학교 재료공학과 박사 후 연수

- 1999년 8월 현재 : 공주대학 교 고분자공학전공 교수

<관심분야>

고분자 구조 및 물성, 고분자 가공, 폴리올레핀

유 영 철(Young Chul You)

[정회원]

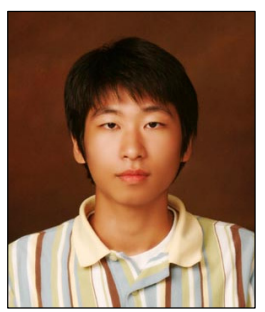

- 2005년 2월 : 남대전 고등학교

졸업

- 2005년 3월 현재 : 공주대학

교 고분자공학전공 학부4년 